Article

\title{
Multi-Modulation of Doxorubicin Resistance in Breast Cancer Cells by Poly(L-histidine)-Based Multifunctional Micelles
}

\author{
Li Jia ${ }^{1,2}{ }^{-}$, Nan Jia ${ }^{1}$, Yan Gao ${ }^{1}$, Haiyang $\mathrm{Hu}^{1}$, Xiuli Zhao ${ }^{1}$, Dawei Chen ${ }^{1}$ and Mingxi Qiao ${ }^{1, *}$ \\ 1 School of Pharmacy, Shenyang Pharmaceutical University, Wenhua Road 103, P.O. Box 42, \\ Shenyang 110016, China \\ 2 Department of Pharmacy, Heze Medical College, Heze 274000, China \\ * Correspondence: qiaomingxi@163.com; Tel.: +86-24-23986308; Fax: +86-24-23986306
}

Received: 6 June 2019; Accepted: 27 July 2019; Published: 2 August 2019

\begin{abstract}
Even though the reversal of multi-drug resistance (MDR) by numerous nanoparticles has been extensively studied, limited success has been achieved. To overcome this barrier, we report a rationally-designed $\mathrm{pH}$-sensitive micelle, in which doxorubicin (Dox) and resveratrol (Res) were co-loaded. The micelle was based on methoxy poly (ethylene glycol)-poly(D,L-lactide)-poly(L-histidine) (mPEG-PLA-PHis), which integrated passive targeting, endo-lysosomal escape and pH-responsive payloads release. At a physiological pH of 7.4 (slightly alkali), Dox and Res were incorporated into the micelles core using the thin-film hydration method ( $\mathrm{pH}$-endoSM/Dox/Res). After cellular uptake, the micelles exhibited an enhanced dissociation in response to the acidic endosomes, triggering the release of Res and Dox. Furthermore, Res was observed to synergistically improve the cytotoxicity of Dox by down-regulating the P-glycoprotein (P-gp) expression, decreasing the membrane potential of the mitochondrial and ATP level, as well as inducing cell apoptosis mediated by mitochondria. The $\mathrm{pH}$-endoSM/Dox/Res showed a prominent ability to decrease the $\mathrm{IC}_{50}$ of Dox by a factor of 17.38 in cell cytotoxicity against the MCF-7/ADR cell line. In vivo distribution demonstrated the excellent tumor-targeting ability of the $\mathrm{pH}$-endoSM/Dox/Res. All results indicated that $\mathrm{pH}$-endoSM/Dox/Res held great potential for the treatment of Dox-resistance breast cancer cells.
\end{abstract}

Keywords: poly(L-histidine); $\mathrm{pH}$ sensitive micelle; MDR

\section{Introduction}

Chemotherapy is still a treatment option for breast cancer, even though its efficacy has been seriously compromised due to the development of multidrug resistance (MDR), as well as the undesirable side effects of chemotherapeutic agents. Even though tremendous research effort has been made to overcome MDR, limited progress has been achieved in clinical studies [1,2]. One of the most challenging aspects in overcoming MDR is that multiple resistant mechanisms can be involved and probably even act jointly [3]. A number of resistant mechanisms have been revealed to contribute to the MDR, such as the ATP binding cassette (ABC) transporters [4], DNA methylation [5], glutathione S-transferase (GST) [6,7] and topoisomerase apoptosis [8]. Among them, membrane transporter-mediated MDR, (including P-glycoprotein(P-gp) [5,9], multidrug resistance-associated protein 1(MRP-1) [9] and breast cancer resistance protein (BCRP)) $[10,11]$ is the most investigated mechanism due to the known clinical significance.

The elucidation of MDR mechanisms led to tremendous studies using various chemosensitizers (MDR modulators) co-administered with chemotherapeutic drugs by nanocarriers to combat MDR [12-14]. For example, various MDR modulators, such as Cremophor EL [15], Tween80 [16], 
TPGS [17] and Pluronic [18] have been used to combat MDR due to their inhibiting effect on the resistant mechanisms.

These MDR modulators have been elucidated to reverse MDR by sensitizing the resistant cancer cells to the cytotoxic drugs $[19,20]$. One of the most distinct advantages offered by the nanocarrier-based co-delivery systems is to enhance the selective accumulation in tumor and to synchronize the Pharmacokinetics profiles of different agents [21-23]. For example, a multifunctional micelle which possessed the targeting ability mediated by folate, effective endo-lysosomal escape and payload releasing modulation in acidic environments, was constructed to co-delivery Dox and Pluronic P85 to reverse the multidrug resistant [14]. Compared with normal micelles, the multifunctional micelles revealed enhanced cytotoxicity against MCF-7/ADR cells because of its capability in overcoming the biological barriers for intracellular payloads delivery [24,25].

However, most MDR reversal studies have been focusing on the reversal of the classical MDR mechanisms by using various MDR modulators [26]. This is probably one of the major reasons for the limited progress in combating MDR because of the failure of addressing the multifactorial nature of MDR. The MDR in the cancer cell was probably caused by more than one resistant mechanism. Therefore, future studies intended for MDR reversal are expecting to address more cellular MDR mechanisms by using more rationally-designed multifunctional nanocarriers to co-deliver MDR modulators and chemotherapeutics agents $[27,28]$.

Resveratrol (Res), a natural phytoalexin obtained widely from the root extracts of Polygonum cuspidatum (buckwheat and knotweed of the Polygonaceae Family) and red grapes, has received significant attention in cancer chemotherapy [29-31]. Previous studies indicate that Res can overcome MDR by modulating apoptotic pathways, downregulating drug transporters and inhibiting cell survival signaling pathways, which make it a promising candidate as an MDR modulator [27-30].

In here, a multifunctional micelle was constructed by the copolymer of mPEG-PLA-PHis for the co-delivery of Dox and Res to exert a synergistic anti-tumor effect in MCF-7/ADR cancer (Scheme 1). The multifunctional micelles were designed to integrate passive targeting, endo-lysosomal escape and $\mathrm{pH}$-triggered payloads release functionalities, in order to overcome the enhanced intracellular sequestration in endo-lysosomes, and to increase the intracellular concentration of payloads. Res was expected to combat multiple resistant mechanisms such as P-gp mediated efflux, over-expressed P-gp and the inhibition of cell apoptosis. The co-encapsulated Dox and Res micelles were prepared and characterized. The possible mechanisms underlying the superior efficiency of the micelles for MDR reversal was also investigated. Furthermore, the biodistribution of the micelles in vivo was evaluated using an orthotopic xenograft human breast cancer model.

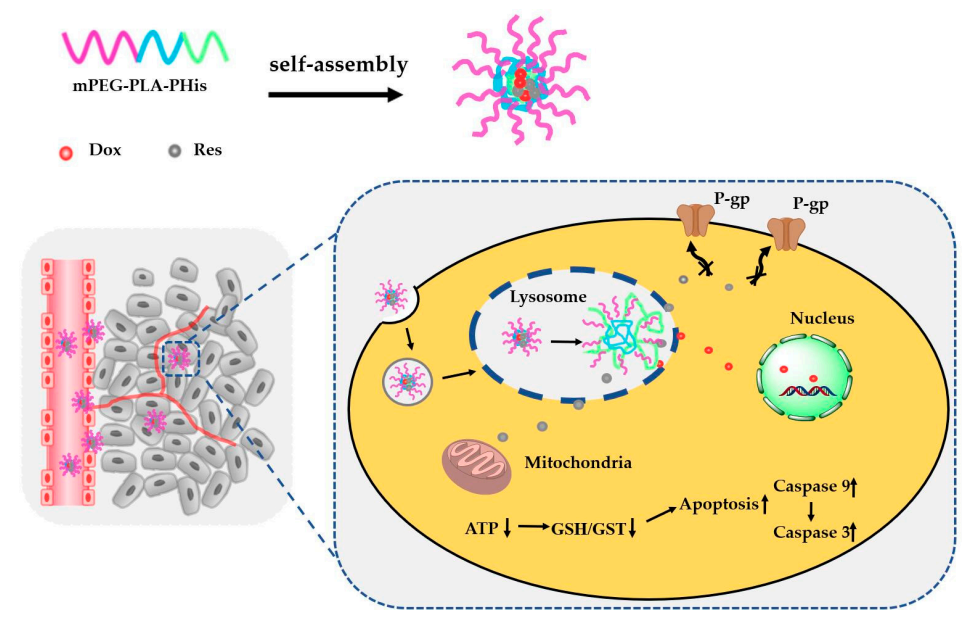

Scheme 1. Schematic representation of the approach to overcome multi-drug resistance (MDR) in breast cancer by a co-delivery of resvertrol (Res) and doxorubicin (Dox) with methoxy poly (ethylene glycol)-poly(D,L-lactide)-poly(L-histidine) (mPEG-PLA-PHis). 


\section{Materials and Experimental Section}

\subsection{Materials}

Doxorubicin (Dox) Hydrochloride was provided by the Zhejiang Hisun Pharmaceutical Co. Ltd. (Taizhou, China). Resveratrol (Res) was purchased from Guan Jie Biotech (Xian, China). N $\alpha-$ CBZ-Nim-DNP-L-histidine was offered by GL Biochem, Ltd. (Shanghai, China). The mPEG2000, $\mathrm{N}, \mathrm{N}^{\prime}$-Carbonyldiimidazole (CDI), Isopropylamine and verapamil (VRP) were obtained from Sigma-Aldrich (Shanghai, China). D,L-Lactide was purchased from Jinan Daigang Biomaterial Co Ltd. (Jinan, China). MTT, the ATP assay kit, the caspase activity test kit and the JC-1-mitochondrial membrane potential assay kit were provided by the Nanjing Jiancheng Bioengineering Institute (Nanjing, China). Lysotracker Green DND-26 and Hoechst 33258 were purchased from Dalian Meilun Biotechnology Co. Ltd. (Dalian, China). FITC-P-glycoprotein was purchased from BD Biosciences (Franklin Lakes, NJ, USA). The reagents used in cell culture were all offered by Solarbio Life Sciences (Beijing, China). Other reagents and chemicals, if not mentioned, were obtained from Concord Technology (Tianjin, China).

\subsection{Tested Formulations, Cell Culture and Animals}

Tested formulations: Dox solution; Res solution; Dox/Res: Dox and Res mixed solution (w/w: 1:1); $\mathrm{pH}$-endoSM/Dox: endosomal $\mathrm{pH}$ sensitive micelles (methoxy poly (ethylene glycol)-poly(D,L-lactide)-poly (L-histidine) (mPEG-PLA-PHis)) loaded with Dox; pH-endoSM/Res: mPEG-PLA-PHis loaded with Res; pH-endoSM/Dox/Res: mPEG-PLA-PHis loaded with Dox and Res.

Cell culture: MCF-7 (human breast adenocarcinoma cell line) and MCF-7/ADR cell (Dox-resistant MCF-7), obtained from Nanjing KeyGen Biotech. Co., LTD. (Nanjing, China), were cultured at $37^{\circ} \mathrm{C}$ in a humidified atmosphere of $5 \% \mathrm{CO}_{2}$ after being cultured in Dulbecco's Modified Eagle's Medium (DMEM) and 1640 medium, respectively. Notably, to maintain the resistant property of the MCF-7/ADR cell line, $1 \mu \mathrm{g} / \mathrm{mL}$ Dox should be added into the medium.

Animals: Female BALB/c-nude mice (20 \pm 2$)$ g were obtained from the Department of Experimental Animals, Shenyang Pharmaceutical University (Shenyang, China). All animal experiments were carried out under the protocols approved by the ethics committee of Shenyang Pharmaceutical University (the project identification code: SYPU-IACUC-C2018-12-7-102, date of approval: 07/12/2018).

\subsection{Synthesis and Characterizations of $\mathrm{pH}$ Sensitive Copolymers}

The copolymer was synthesized according to the procedure described in our previous study [27]. The chemical structure was confirmed by ${ }^{1} \mathrm{H}$ nuclear magnetic resonance spectra in $\mathrm{CDCL}_{3}-\mathrm{d}$ using Bruker DRX-600. The average molecular weights (Mw) and polydispersity index (PDI) of the copolymer was determined by the gel permeation chromatography (GPC) by Agilent 1200 series system.

\subsection{Preparation and Incorporation Payloads into Micelles}

The payloads were incorporated to the copolymer micelles by the thin-film hydration method [32]. First, Dox base was prepared by a dropwise addition of triethylamine $(10 \mu \mathrm{L}$ for per $10 \mathrm{mg}$ Dox $\cdot \mathrm{HCl}$ into the Dox $\mathrm{HCl}$ aqueous solution $(50 \mathrm{mg} / \mathrm{mL})$ and extracted with $\left.\mathrm{CHCl}_{3}\right)$ [33]. Then $2 \mathrm{mg}$ of Dox and Res $(1 / 1, w / w)$ were added to $10 \mathrm{mg}$ of mPEG-PLA-PHis in $10 \mathrm{~mL}$ of dichloromethane. The mixture was sonicated for $30 \mathrm{~min}$. A thin film was obtained by rotary evaporation at $15{ }^{\circ} \mathrm{C}$ followed by hydrating with $10 \mathrm{~mL}$ of phosphate buffer saline (pH 7.4) (slightly alkali) for $20 \mathrm{~min}$ in order to obtain the payloads-incorporated micelles. The micellar solution was centrifugated at $9600 \times g$ for $10 \mathrm{~min}$. The final micellar solution was collected by filtrating through a $0.45 \mu \mathrm{m}$ membrane film.

Reference micelles were prepared by the same process, except that either $1 \mathrm{mg}$ of Dox or $1 \mathrm{mg}$ of Res was mixed with mPEG-PLA-PHis. The blank micelles were prepared with the same process, but this time eliminating the incorporation of payloads. DIR-incorporated micelles were obtained by mixing $0.1 \mathrm{mg}$ of DIR with mPEG-PLA-PHis. 


\subsection{Characterization of Copolymer Micelles}

The encapsulation efficiency of Dox and Res, respectively, were determined by an ultracentrifugation method [34]. The micelle solutions were placed into centrifuge tubes and centrifugated at the speed of $12,000 \mathrm{rpm}$ for $10 \mathrm{~min}$. Then, the supernatants were collected and passed through a $0.22 \mu \mathrm{m}$ Millipore filter. The filtrate was transferred to a $10 \mathrm{~mL}$ volumetric flask and diluted with methanol to volume. The amount of free Dox and total Dox, respectively, were measured by a multifunctional microplate reader (Tecan, Austria) $(E x=470 \mathrm{~nm}$; $E m=585 \mathrm{~nm})$, while the amount of Res was analyzed by high-performance liquid chromatography (HPLC) with a detection wavelength of $306 \mathrm{~nm}$. The encapsulation efficiency (EE\%) and drug loading content (DL\%) of Dox and Res were calculated using the following equations

$$
\begin{gathered}
\mathrm{EE} \%=\frac{\mathrm{m}_{1}}{\mathrm{~m}_{2}} \times 100 \% \\
\mathrm{DL} \%=\frac{\mathrm{m}_{1}}{\mathrm{~m}_{2}+\mathrm{m}_{3}} \times 100 \%
\end{gathered}
$$

where, $\mathrm{m}_{1}$ is the weight of the encapsulated payload, $\mathrm{m}_{2}$ the weight of the feeding payload and $\mathrm{m}_{3}$ is the weight of copolymer.

Furthermore, the zeta-potential, particle size and its distribution of the pH-endoSM/Dox/Res micelle were characterized using dynamic light scattering (Malvern Zetasizer Nano ZS instrument, UK) subsequent to appropriate dilution. After the samples were prepared on the copper mesh by being negatively stained with $2 \%$ sodium phosphotungstate, the morphology feature of pH-endoSM/Dox/Res was captured by a transmission electron microscope (TEM, JEOL Ltd., Tokyo, Japan).

\subsection{In Vitro Release of Dox and Res from Micelles}

The dialysis method was used to investigate the Dox and Res release according to a previous report [35]. In brief, Dox, Res and pH-endoSM/Dox/Res were transferred into the dialysis bags (MWCO $3500 \mathrm{Da})$ and then immersed in $50 \mathrm{~mL}$ of phosphate-buffered saline (PBS) at different pH levels (0.01 M, $\mathrm{pH} 7.4,6.5,5.0)$, respectively. Then $0.5 \%(w / v)$ of Tween 80 was added in dissolution media to satisfy sink conditions. The system was kept at $37^{\circ} \mathrm{C}$ under a shaking of $100 \mathrm{rpm}$. At each predetermined point, $2 \mathrm{~mL}$ of released medium was sampled and replaced with $2 \mathrm{~mL}$ of fresh medium. The amount of Dox and Res in the sample were assayed as described before.

\subsection{In Vitro Cytotoxicity Study}

MCF-7 and MCF-7/ADR cell lines (obtained from Nanjing KeyGen Biotech. Co., LTD.) were used to assess the cytotoxicity of various formulations in vitro [36]. MCF-7 $\left(0.7 \times 10^{4}\right.$ per well $)$ and MCF-7/ADR cell $\left(1.4 \times 10^{4}\right.$ per well) were well seeded and incubated in 96-well plates with five replicates for one night. Then, Dox, Res, $\mathrm{pH}$-endoSM/Dox and $\mathrm{pH}$-endoSM/Dox/Res, respectively, were co-incubated with MCF-7 and MCF-7/ADR cells in 96-well plates at various concentrations for 48h. The original medium was replaced with the fresh medium $(200 \mu \mathrm{L})$ containing $10 \%$ MTT solution and reacted with cells for another $4 \mathrm{~h}$. Finally, the medium was replaced with dimethyl sulfoxide (DMSO) $(150 \mu \mathrm{L})$ to dissolve the formazan crystals formed in the viable cells. The untreated wells and untreated cells were used as blank and control, respectively. The optical density (OD) value at 570 $\mathrm{nm}$ was recorded by a microplate reader. The cell viability was calculated according to Equation (3). The resistance index (RI) of MCF-7/ADR cell was calculated according to Equation (4). The $\mathrm{IC}_{50}$ value of each sample was calculated by SPSS 17.0 (Chicago, IL, USA).

$$
\begin{gathered}
\text { Cell viability }=\frac{\mathrm{OD}_{\text {treat }}-\mathrm{OD}_{\text {blank }}}{\mathrm{OD}_{\text {control }}-\mathrm{OD}_{\text {blank }}} \times 100 \% \\
\mathrm{RI}=\frac{\mathrm{IC}_{50}(\mathrm{MCF} / \mathrm{ADR})}{\mathrm{IC}_{50}(\mathrm{MCF})}
\end{gathered}
$$




\subsection{Intracellular Influx of Dox}

To measure the intracellular influx of Dox, the flow cytometry analysis was performed. MCF-7/ADR cells $\left(1 \times 10^{5}\right.$ per well) in logarithmic phase were seeded in 6-well plates with three replicates and incubated for $24 \mathrm{~h}$. Then, $\mathrm{PH}$-endoSM/Dox/Res (Dox concentration: $5.0 \mathrm{mg} / \mathrm{mL}$ ) was added to the wells. The untreated wells were served as the blank and Dox and Dox/Res-treated wells were served as a control. After being incubated for $6 \mathrm{~h}$, the cells were harvested, washed with PBS thrice and resuspended in $0.5 \mathrm{~mL}$ of PBS. The samples were detected by flow cytometry (BD Biosciences, San Jose, CA, USA) to quantify the internalized Dox.

\subsection{Cellular Uptake and Intracellular Trafficking}

Confocal laser scanning microscopy (CLSM) was used to investigate the cellular uptake and intracellular trafficking of Dox delivered by different formulations [37]. The Dox solution-treated group was used as a control. The MCF-7/ADR cells $\left(2 \times 10^{4}\right.$ per well) were seeded on coverslips placed in a 6-well plate and cultured overnight. Dox solutions and $\mathrm{pH}$-endoSM/Dox/Res (Dox concentration: $5.0 \mathrm{mg} / \mathrm{mL}$ ) were added to the wells and incubated for $15 \mathrm{~min}, 30 \mathrm{~min}, 1 \mathrm{~h}, 2 \mathrm{~h}, 4 \mathrm{~h}$ and $6 \mathrm{~h}$ at $37^{\circ} \mathrm{C}$, respectively. After being washed with PBS thrice, the cells in the coverslips were treated with LysoTracker green DND for $30 \mathrm{~min}$ to visualize endo/lysosomes. Subsequently, the cells were washed by PBS to remove the excess stain, fixed with paraformaldehyde solution ( $4 \%, 0.01 \mathrm{M}$ PBS), and stained with Hoechst 33258 for 10 min, followed by being captured using CLSM (Olympus FV1000-IX81, Japan).

\subsection{P-gp Expression Determination}

The P-glycoprotein (P-gp) expression of various formulations were detected by Flow cytometry [38]. The gene silencing efficiency was also detected by Flow cytometry. MCF-7/ADR cells $\left(1 \times 10^{5}\right.$ per well $)$ were seeded and cultured in 6-well plates for $24 \mathrm{~h}$. Dox, Res, Dox/Res and pH-endoSM/Dox/Res were added and incubated for $6 \mathrm{~h}$ (Dox concentration: $5.0 \mathrm{mg} / \mathrm{mL}$ ). Verapamil (calcium antagonists and multi-drug resistance (MDR) reversal agent) was used as a positive control. The cells were harvested, washed with PBS thrice and resuspended in $0.5 \mathrm{~mL}$ of PBS. Then the samples were detected after having been treated with $20 \mu \mathrm{L}$ FITC-labeled P-gp monoclonal antibody at $4{ }^{\circ} \mathrm{C}$ for $30 \mathrm{~min}$.

\subsection{Mitochondrial Membrane Potential Detection}

The fluorochrome JC-1(5,5',6,6'-Tetrachloro-1,1',3,3'-tetraethyl-imidacarbocyanine iodide) was used to detect the mitochondrial membrane potential 1 [39,40]. MCF-7/ADR cells $\left(1 \times 10^{6}\right.$ per well $)$ were planted in 6-well plates. After $24 \mathrm{~h}$ proliferation, Res, Dox, Dox/Res and $\mathrm{pH}$-endoSM/Dox/Res were added to the cells for $2 \mathrm{~h}$ (Dox concentration: $5.0 \mathrm{mg} / \mathrm{mL}$ ). The negative and positive control groups were the fresh culture medium and CCCP (Mitochondrial electron transfer chain inhibitor), respectively. After incubation for $6 \mathrm{~h}$, JC-1 work solution $(10 \mathrm{mg} / \mathrm{mL})$ was added and incubated for another $20 \mathrm{~min}$ in dark at $37^{\circ} \mathrm{C}$. Then the cells were harvested and washed twice with JC-1 buffer solution. The fluorescence intensities of red $(E x=488 \mathrm{~nm}, E m=590 \mathrm{~nm})$ and green $(E x=488 \mathrm{~nm}, \mathrm{Em}=$ $530 \mathrm{~nm}$ ) were detected by a multifunctional microplate reader. The ratio of red to green was calculated and defined as the JC-1 fluorescence intensity ratio.

\subsection{ATP Contents Assay}

According to the ATP assay kit, the ATP content in the cells was determined by fluoresceinluciferase assay [18,34]. MCF-7/ADR cells $\left(1 \times 10^{6}\right.$ per well $)$ were planted and incubated in 6-well plates for $24 \mathrm{~h}$. Then the cells were exposed to Dox, Res, Dox/Res and $\mathrm{pH}$-endoSM/Dox/Res, and the culture solution was used as a negative control (Dox concentration: $5.0 \mathrm{mg} / \mathrm{mL}$ ). After $2 \mathrm{~h}$ incubation, the cells were washed with pre-chilled PBS thrice and cell lysate was added. The supernatant was collected after centrifugation. Then, $50 \mu \mathrm{L}$ of sample and $150 \mu \mathrm{L}$ of ATP-monitoring working solutions were added and measured by a multifunctional microplate reader according to the operation manual 
of the ATP assay kit. The BCA kit was used to normalize the protein content and the ATP content in the samples was calculated by a pre-made standard curve.

\subsection{Caspase Activity Assays}

According to the caspase activity test kit instructions, MCF-7/ADR cells were planted and cultured in 6-well plates for $24 \mathrm{~h}$, then co-incubated with Dox solution, Res solution, Dox/Res and $\mathrm{pH}$-endoSM/Dox/Res for another $24 \mathrm{~h}$. Blank medium was served as the control group. After being lysed and centrifuged at $9600 \times g$ for $1 \mathrm{~min}$ at $4{ }^{\circ} \mathrm{C}$, the supernatants were collected and interacted with the peptide substrates of caspase 3, caspase 8 and caspase 9, respectively. The activities of caspase were calculated based on the absorbance values at $405 \mathrm{~nm}$ of reactants detected by a microplate reader.

\subsection{Biodistribution of pHendo-Sensitive Micelles In Vivo}

To investigate the biodistribution of $\mathrm{pH}$-endo-sensitive micelles, the MCF-7/ADR cells were injected subcutaneously into the right axillary fossa of female BALB/c nude mice $\left(\left(1 \times 10^{6}\right.\right.$ per $200 \mu \mathrm{L}$ PBS). When the tumor size reached $150-200 \mathrm{~mm}^{3}$, DIR-loaded micelles $(0.1 \mathrm{mg} / \mathrm{mL})$ were injected though the tail vein of the MCF-7/ADR xenograft nude mice. The Kodak In Vivo Imaging System FX $\mathrm{PRO}$ was used to image tumor-bearing nude mice with the wavelength at Ex/Em 720/790 nm after anesthesia. The time-dependent fluorescence distribution was detected at $0.5,1,2,4,8,12,24,36,48 \mathrm{~h}$ after injection. After $48 \mathrm{~h}, \mathrm{BALB} / \mathrm{c}$ nude mice were sacrificed. The major organs and tumors were collected under anesthesia for ex vivo fluorescence imaging.

To further verify the tumor targeting ability of $\mathrm{pH}$-endoSM/Dox/Res in vivo, the tumor-bearing mice were injected with Dox solution, $\mathrm{pH}$-endoSM/Dox and $\mathrm{pH}$-endoSM/Dox/Res, respectively (Dox: $5.0 \mathrm{mg} / \mathrm{kg}$ ). The mice were sacrificed after $48 \mathrm{~h}$, and the Dox fluorescence signals of the main organs and tumor tissues were detected (Ex: $497 \mathrm{~nm}$; Em: $588 \mathrm{~nm}$ ).

\subsection{In Vivo Antitumor Efficacy and Safety Evaluation}

The MCF-7/ADR tumor-bearing mice model was established as described above. The mice were randomly divided into four groups (five mice per group) when the tumor grew to about $100 \mathrm{~mm}^{3}$. The four groups were intravenously injected with saline, Dox solution, $\mathrm{pH}$-endoSM/Dox and $\mathrm{pH}$-endoSM/Dox/Res, respectively (Dox: $5.0 \mathrm{mg} / \mathrm{kg}$ ). After $48 \mathrm{~h}$, these mice were sacrificed, and then tumor tissues and the main organs were harvested and weighted. The tumor inhibition rates (TIR\%) were calculated by the following formula. Finally, the major organs and tumor tissue were fixed with $4 \%$ paraformaldehyde for hematoxylin and eosin (H\&E) staining according the manufacturer information. Tissue sections were observed and imaged using an inverted microscope.

$$
\mathrm{TIR} \%=\frac{W c-W t}{W c} \times 100 \%
$$

where $W c$ and $W t$ represent the tumor weight of the control group and the treated groups, respectively.

\subsection{Statistical Analysis}

Quantitative results were all expressed as mean \pm standard deviation. Statistical analysis was determined by one-way analysis of variance (ANOVA) and Student's $t$-test among each group (SPSS 17.0 software, SPSS Inc.). A $p$ value smaller than 0.05 was considered statistically significant.

\section{Results and Discussion}

\subsection{Characterizations of mPEG-PLA-PHis by Proton Nuclear Magnetic Resonance $\left({ }^{1} H-N M R\right)$ and GPC}

The nuclear magnetic resonance spectroscopy (NMR) spectrum of copolymer was presented in Figure $1 \mathrm{~A}$ with $\mathrm{CDCl}_{3}$ as the solvent. The peaks at $\delta$ e are at $5.24 \mathrm{ppm}, \delta \mathrm{d}$ at $3.67 \mathrm{ppm}, \delta \mathrm{c} 3.47$ and 
$\delta$ being 1.83 ppm, were attributed to mPEG-PLA $\left(-\mathrm{COCH}\left(\mathrm{CH}_{3}\right) \mathrm{O}-,-\mathrm{OCH}_{2} \mathrm{CH}_{2} \mathrm{O}-,-\mathrm{OCH}_{3}\right.$ and $-\mathrm{COCH}\left(\mathrm{CH}_{3}\right) \mathrm{O}-$, respectively). The intensity ratio of PLA at $\delta \mathrm{e}=5.24 \mathrm{ppm}\left(-\mathrm{COCH}\left(\mathrm{CH}_{3}\right)\right.$ and $\mathrm{mPEG}$ at $\delta \mathrm{c} 3.47 \mathrm{ppm}\left(-\mathrm{OCH}_{3}\right)$ represented the degree of PLA block [41]. Two typical chemical shifts appeared at $\delta \mathrm{a} 1.55 \mathrm{ppm}\left(-\mathrm{C}\left(\mathrm{CH}_{3}\right)_{2}-\right)$ and $\delta \mathrm{g} 4.35 \mathrm{ppm}(-\mathrm{CH}-\mathrm{NH}-)$ and indicated the successful connection of PHis block to the PLA block. Based on the intensity ratio of $\delta \mathrm{a} 1.55 \mathrm{ppm}$ to $\delta \mathrm{g} 4.35 \mathrm{ppm}$, the polymerization degree of poly(L-histidine) was determined to be 6 . As shown in Figure 1B, gel permeation chromatography (GPC) also demonstrated the successful synthesis of the copolymer with Mw of 5511 and a low PDI.<smiles>COCCOC(=O)C(C)OC(=O)N[C@@H]([I-]c1c[nH]cn1)C(=O)NC(C)C</smiles>
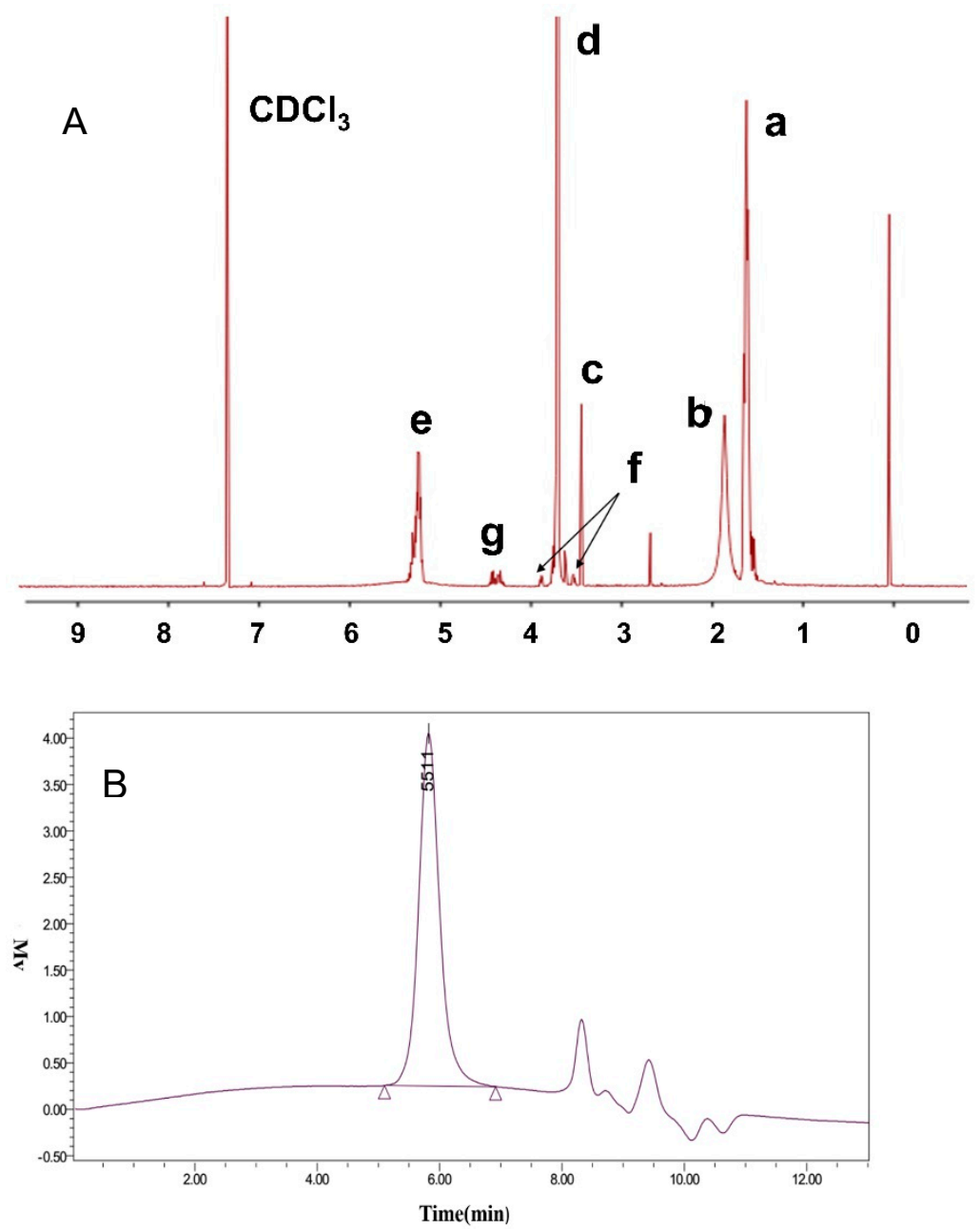

Figure 1. Typical proton nuclear magnetic resonance $\left({ }^{1} \mathrm{H}-\mathrm{NMR}\right)$ spectrum $(\mathbf{A})$ and gel permeation chromatography (GPC) spectrum (B) of mPEG-PLA-PHis copolymer. 


\subsection{Characterization of the Micelles}

The characterization results of $\mathrm{pH}$-endoSM/Dox/Res are shown in Table 1. The EE\% values of Dox and Res in the mPEG-PLA-PHis micelles were above $80 \%$ respectively, indicating a good payload encapsulation. The dynamic light scattering test of Dox/Res-loaded micelles showed average an particle size of $75 \mathrm{~nm}$ with unimodal distribution (Figure 2A). The Dox/Res-loaded micelles were spherical particles with an average size of around $50 \mathrm{~nm}$, as demonstrated by transmission electron microscope (TEM) images (Figure 2B).

Table 1. The physicochemical characterization results of the micelles.

\begin{tabular}{cccccc}
\hline \multirow{2}{*}{ Formulation } & \multirow{2}{*}{ Particle Size (nm) } & \multicolumn{2}{c}{ EE\% } & \multicolumn{2}{c}{ DL\% } \\
\cline { 3 - 6 } & & Dox & Res & Dox & Res \\
\hline pH-endoSM/Dox & $52.7 \pm 0.22$ & $95.2 \pm 0.81$ & - & $8.63 \pm 0.22$ & - \\
$\mathrm{pH}-$-endoSM/Dox/Res & $75.1 \pm 0.32$ & $80.2 \pm 0.38$ & $82.3 \pm 0.71$ & $6.92 \pm 0.12$ & $7.10 \pm 0.20$ \\
\hline
\end{tabular}
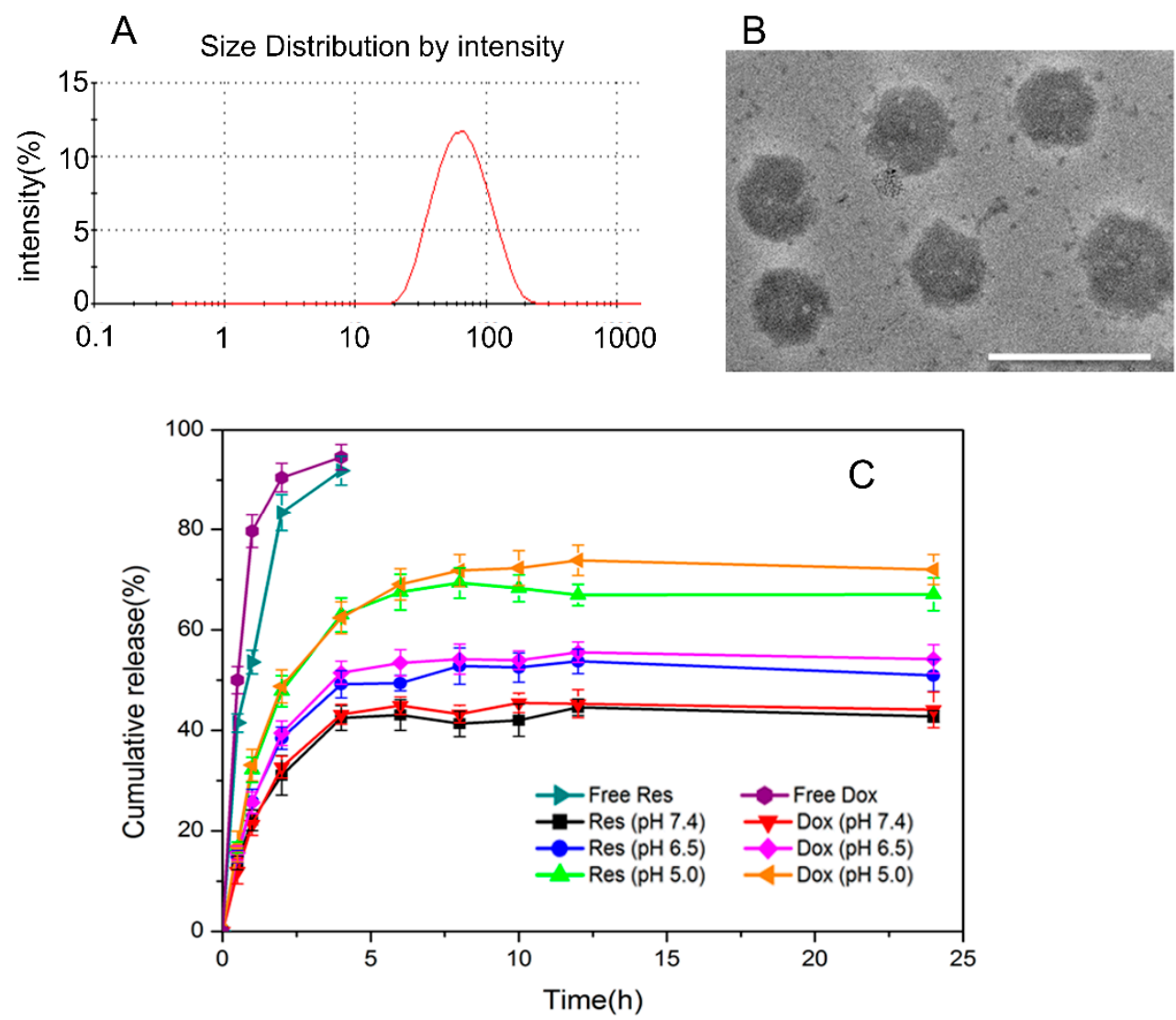

Figure 2. Particle size distribution (A) and transmission electron microscopy (TEM) image of $\mathrm{pH}$-endoSM/Dox/Res micelles. Scale bar represents $100 \mathrm{~nm}(\mathbf{B})$. In vitro release profiles of Dox and Res from the $\mathrm{pH}$-endoSM/Dox/Res micelles in phosphate-buffered saline (PBS) (pH 7.4, 6.5 and 5.0) at $37^{\circ} \mathrm{C}$. The data are presented as means $(\%) \pm$ SD from three independent experiments $(\mathbf{C})$.

The release of Dox and Res from the micelles were investigated at different $\mathrm{pH}$ conditions simulating the biological $\mathrm{pH}(7.4)$ and acidic tumor $\mathrm{pH}(6.5,5.5)$. Prior to conducting the release tests, the Dox and Res releases from the stock solution were tested. Non-encapsulated drugs were completely released within $4 \mathrm{~h}$, indicating the free diffusion of drug molecules across the dialysis membrane independent of $\mathrm{pH}$. As shown in Figure 2C, $\mathrm{pH}$-endoSM/Dox/Res micelles showed burst release $(\sim 30 \%)$ in $4 \mathrm{~h}$, followed by a typically sustained release at $\mathrm{pH} 7.4$ (slightly alkali). 
The cumulative payload release only reached around $40 \%$ after $24 \mathrm{~h}$, indicating the good stability and low payload leakage of the micelles. However, as the $\mathrm{pH}$ declined from 7.4 to 5.5 (from alkali to acidic), the cumulative payload released remarkedly increased to $\sim 70 \%$, as compared to that at $\mathrm{pH} 7.4$ at $24 \mathrm{~h}$. The $\mathrm{pH}$-accelerated payload release was caused by the dissociation of the imidazole group of PHis blocks, which induced the disorder of micellar structure [35]. The dissociation extent of PHis blocks was closely related to the environment $\mathrm{pH}$. As the $\mathrm{pH}$ decreased, more imidazole groups would become dissociated, resulting in a higher extent of dissociation and more severe micellar structure disorder [41]. Therefore, the micelles showed a much faster payload release at pH 5.0 than that at $\mathrm{pH}$ 6.5. The similar $\mathrm{pH}$-triggered release characteristics of Dox and Res indicate the potential of $\mathrm{pH}$-endoSM/Dox/Res as a carrier for the co-delivery of agents with different physiochemical properties and the manipulation of Pharmacokinetics/Pharmacodynamics (PK/PD) properties for achieving the synergistic effect.

\subsection{Enhanced Cytotoxicity Against MCF-7/ADR}

In advance of the cytotoxicity test, the resistance characteristic of the cells was first investigated. According to the $\mathrm{IC}_{50}$ values (inhibitory concentration to reduce cell survival to $50 \%$ ), the resistance index (RI) of the MCF-7/ADR cells was calculated to be 62.67, demonstrating that the cells possessed strong resistance to Dox.

The cytotoxicity of different formulations against MCF-7/ADR cells was determined by the MTT method. As shown in Figure 3A,B, as the concentration of Res and Dox increased, the cell viability of the MCF-7/ADR cell were both sharply decreased, indicating that the cytotoxicity of Res and Dox presented dose-dependent property. The concentration of Res was set to $10 \mu \mathrm{g} / \mathrm{mL}$ for the following studies due to the moderate cytotoxicity at this concentration. The antitumor effect of Dox against resistant cancer cells could be further reinforced by the presence of Res (Figure 3C). The results showed that the Dox/Res at the ratio of 1:1 (w:w) exhibited the best synergistic effect. Therefore, this Dox/Res ratio was chosen for the following studies.

The blank micelles showed good biocompatibility as characterized by more than $90 \%$ cell viability (data not shown). The cell cytotoxicity and $\mathrm{IC}_{50}$ values of the $\mathrm{pH}$-endoSM/Dox and $\mathrm{pH}$-endoSM/Dox /Res micelles against MCF-7/ADR cells were shown in Figure 3C and Table 2. The pH-endoSM/Dox/Res showed much lower $\mathrm{IC}_{50}$ value and higher RF compared to Dox solution and $\mathrm{pH}$-endoSM/Dox $(p<0.05)$, demonstrating that the cytotoxicity against the resistant cells could be remarkably enhanced by co-delivery of Res [31].

Table 2. The $\mathrm{IC}_{50}$ and Resistance factor (RF) on the MCF-7/ADR cells.

\begin{tabular}{ccc}
\hline Formulation & IC $_{\mathbf{5 0}}$ & RF \\
\hline Dox solution & $131.60 \pm 4.12$ & - \\
pH-endoSM/Dox & $36.30 \pm 1.16$ & 3.63 \\
pH-endoSM/Dox/Res & $7.57 \pm 0.63$ & 17.38 \\
\hline
\end{tabular}



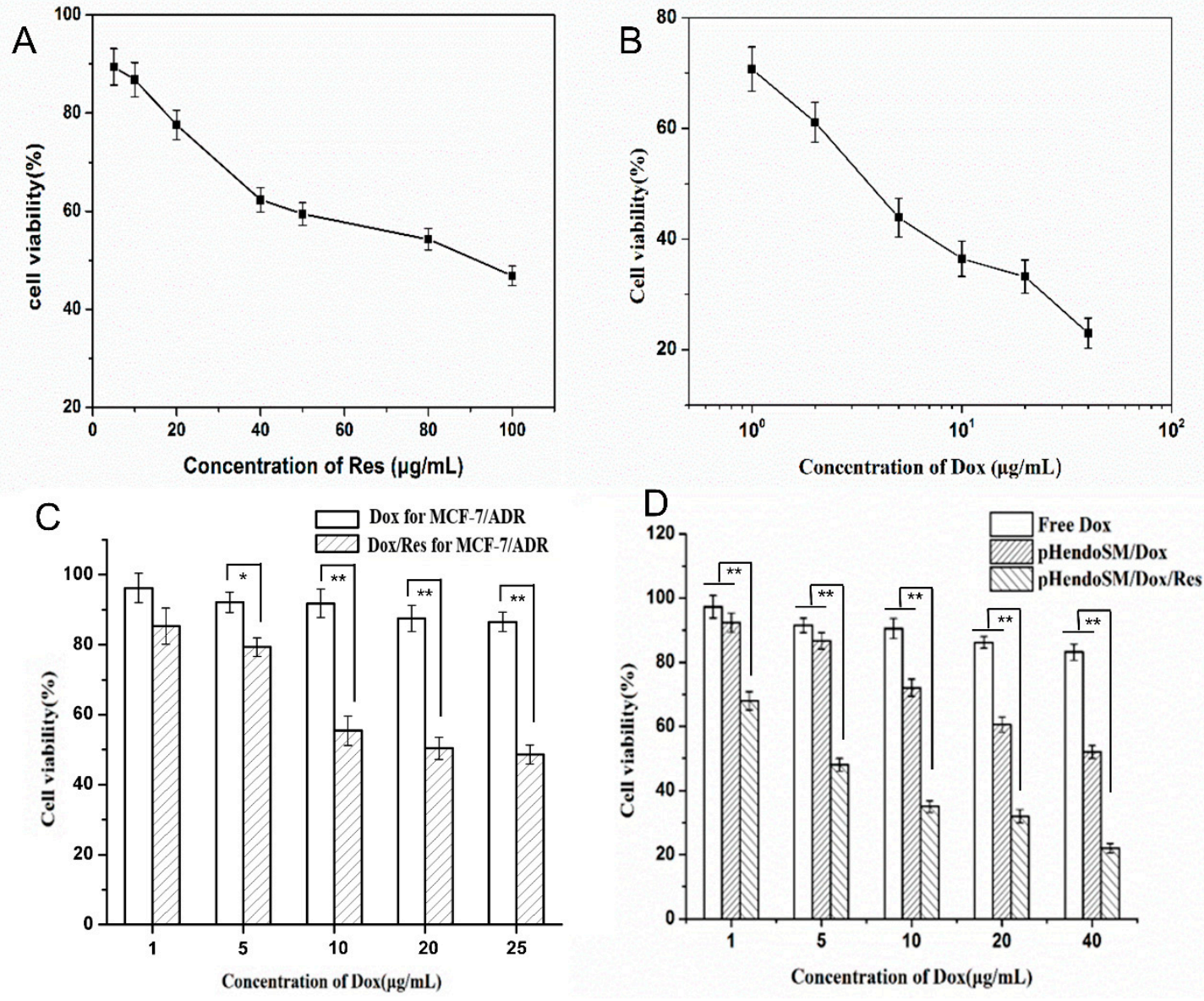

Figure 3. In vitro cytotoxicity of free Res (A), free Dox (B), combination of different proportions of Dox and Res (The concentration of Res was kept at $10 \mu \mathrm{g} / \mathrm{mL}$ ) (C). pH-endoSM/Dox and pH-endoSM/Dox/Res (D). All experiments were tested on MCF-7/ADR cells after $48 \mathrm{~h}$ incubation. Cell viability (\%) was expressed as a percentage compared to the untreated control cells. All data are expressed as mean values \pm SD of 5 independent experiments, ${ }^{*} p<0.05,{ }^{* *} p<0.01$ compared with the control group.

\subsection{Mechanisms for Reverting MDR}

\subsubsection{Cellular Uptake and Intracellular Dox Accumulation}

Flow cytometry and CLSM were first used to examine the intracellular Dox accumulation. After co-incubation with different formulations, the fluorescence signals of Dox inside the MCF-7/ADR cells were recorded (Figure 4A). The moderate MDR reversal observed with $\mathrm{pH}$-endoSM/Dox was attributed to the endocytosis pathway of the micelles which partially bypass the efflux effect caused by a series of efflux pumps such as $\mathrm{P}$-glycoprotein (P-gp) and the $\mathrm{pH}$-triggered payload release, leading to the increased cumulation of Dox and Res in the cells. Furthermore, co-delivered Res markedly increased the intracellular influx of Dox by 5.25 -fold, indicating that Res was capable of inhibiting the efflux of Dox. Therefore, these mechanisms endowed the micelle with a higher intracellular Dox accumulation than the Dox solution [42].

Besides, CLSM was also used to investigate the internalization and subcellular distribution of Dox. For the sake of observation, Hoechst 33258 (nucleus selective dye, blue) and LysoTracker DND-26 (endo-lysosome selective dye, green) were utilized to stain the nucleus and endosome, respectively. After cellular incubation with $\mathrm{pH}$-endoSM/Dox/Res and Dox solution for different time intervals, the fluorescence signals were captured and presented as microphotographs in Figure 4B. The $\mathrm{pH}$-endoSM/Dox/Res group showed weak yellow fluorescence (overlap of Dox with LysoTracker) after 30 min of incubation, indicating that Dox did accumulate in endosomes after endocytosis. The 
gradually increased red fluorescence of Dox and yellow fluorescence in merged images with incubation suggested the gradual accumulation of micelles in the endosomes. As the incubation time reached $6 \mathrm{~h}$, the $\mathrm{pH}$-endoSM/Dox/Res-treated group showed the overlapped Dox signal with the Hoechst 33258 signal, which revealed an apparent purple fluorescence, indicating that Dox escaped from endosomes and distributed into the nuclei. The higher intracellular Dox induced by the mPEG-PLA-PHis micelle could be attributed to the endocytosis pathway of the micelles, an acidic $\mathrm{pH}$-triggered payload release, as well as the co-delivery of Res that showed the MDR reversal effect [39].
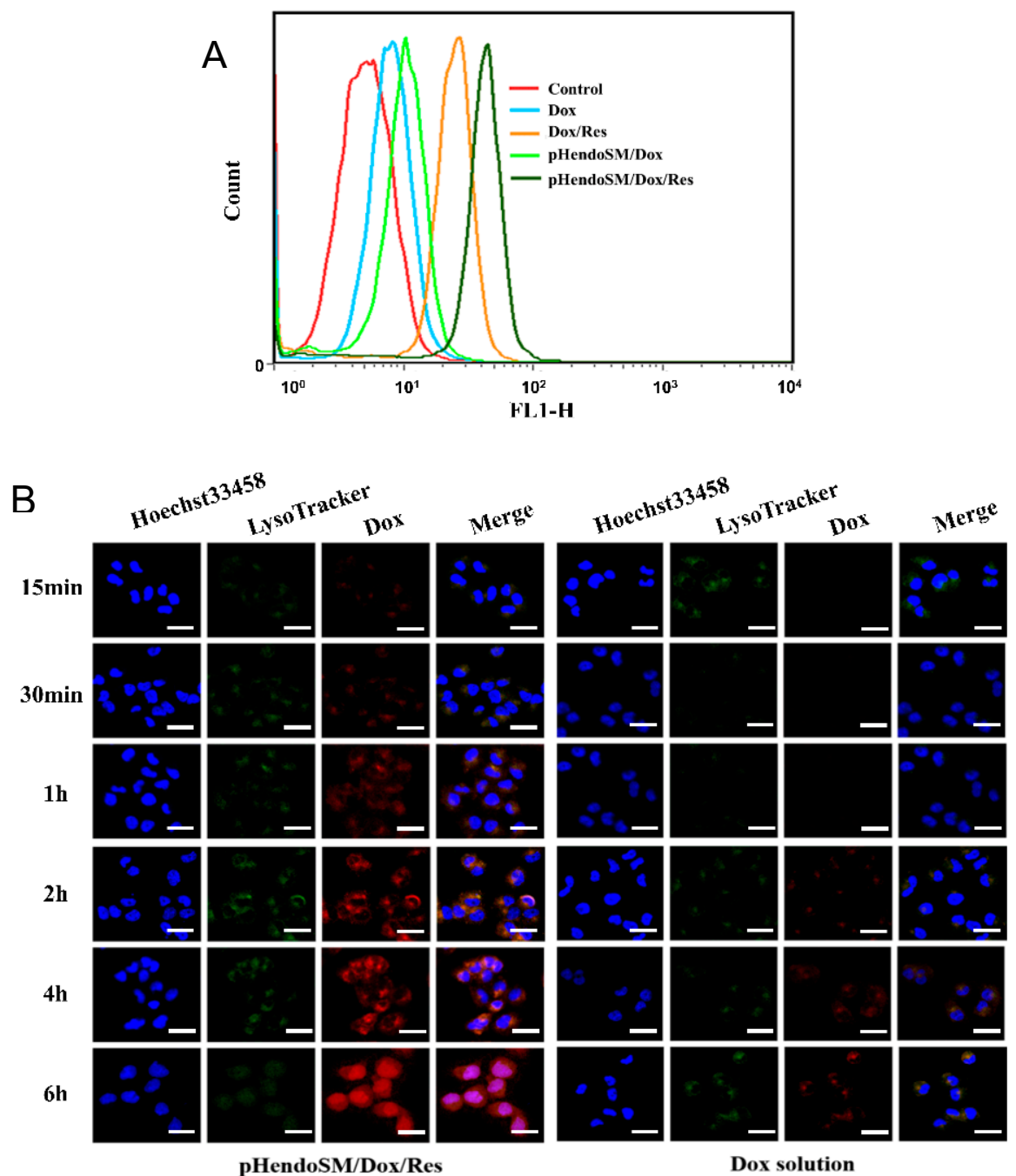

Figure 4. Flow cytometry measurement of the intracellular uptake of Dox in the MCF-7/ADR cells treated with different formulations after $6 \mathrm{~h}$ incubation (A). The confocal laser scanning microscopy (CLSM) images of the MCF-7/ADR cells incubated with $\mathrm{pH}$-endoSM/Dox/Res micelles and free Dox solution for $15 \mathrm{~min}, 30 \mathrm{~min}, 1 \mathrm{~h}, 2 \mathrm{~h}, 4 \mathrm{~h}$, and $6 \mathrm{~h}$ at $37^{\circ} \mathrm{C}$ (Dox concentration was kept at $2 \mu \mathrm{g} / \mathrm{mL}$ ). Blue, green and red colors indicate Hoechst 33342, LysoTracker green and Dox, respectively. Scale bars represent $20 \mu \mathrm{m}(\mathbf{B})$.

\subsubsection{Effect on P-gp Expression}

To further assess the cellular mechanisms for reverting the MDR, P-gp expression inside the MCF-7/ADR cells was investigated by flow cytometry with Ver (a competitive P-gp inhibitor) as a positive control. As seen in Figure 5, Res, Dox/Res and the $\mathrm{pH}$-endoSM/Dox/Res micelles group showed significantly lower P-gp expression compared with our control group $(p<0.05)$, while this 
difference was not significant in the Dox group $(p>0.05)$, demonstrating that Res was capable of down regulating the P-gp expression for MDR reversal.

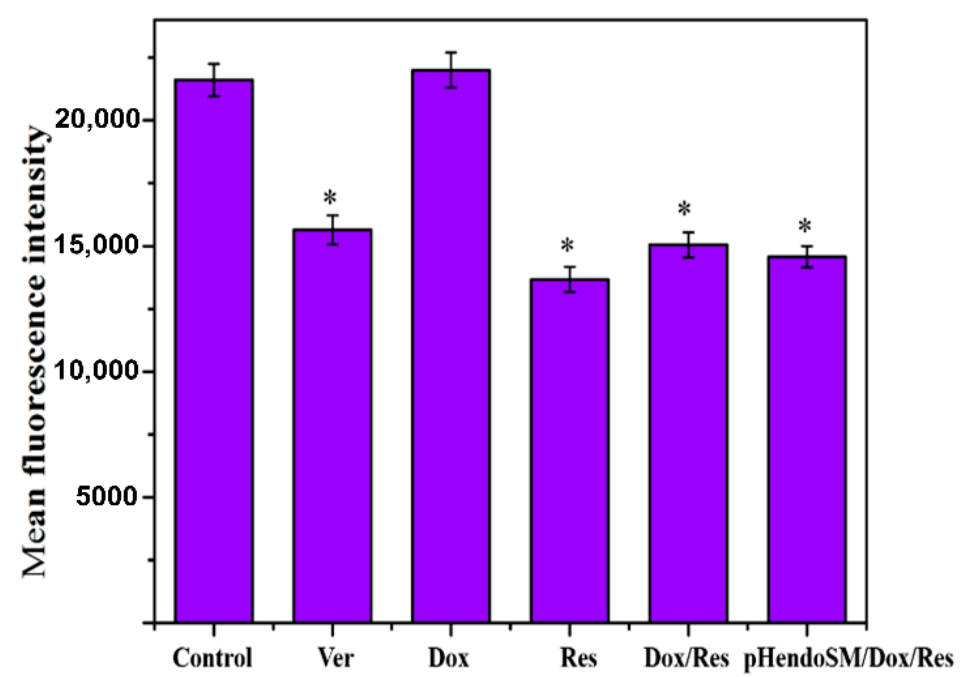

Figure 5. P-glycoprotein(P-gp) expression following treatment with Dox, Res, Dox/Res and $\mathrm{pH}$-endoSM/Dox/Res micelles for $6 \mathrm{~h}$ in MCF-7/ADR cells. FITC-P-gp was performed and green fluorescence was detected by flow cytometry. Data were expressed as mean $\pm \operatorname{SD}(n=3),{ }^{*} p<0.05$, compared with the control group.

\subsubsection{Effect on Energy Metabolism Mediated by Mitochondria}

P-glycoprotein (P-gp) pumps cytotoxic drugs out of cells with the help of ATP, leading to the reduced intracellular drug accumulation and cells resistance to the drugs [43]. The energy of P-gp comes from ATP that is produced by mitochondrial oxidative phosphorylation [44]. Therefore, the effect of the Dox/Res incorporated micelles on cellular energy metabolism in resistant cancer cells was investigated.

A JC-1 fluorescent probe was utilized to detect the mitochondrial membrane potential. The existing form of JC-1 varies with the level of mitochondrial membrane potential and presents different fluorescence which helps to visualize the membrane potential. At normal conditions, the potential of the mitochondrial membrane is relatively high and the JC-1 probe presents red fluorescence. When the potential decreases, it presents green fluorescence. The red/green fluorescence intensity ratio decrease indicates the mitochondrial depolarization (non-functional mitochondria).

As shown in Figure 6A, all formulation groups containing Res showed a significant difference $(p<0.05)$ in decreasing the mitochondrial membrane potential compared to the control group, indicating that Res could disturb energy production by mitochondrial.

To inspect this effect, the ATP level inside the MCF-7/ADR cells was further detected. It could be seen in Figure 6B, the $\mathrm{pH}$-endoSM/Dox/Res group showed the strongest inhibition on the ATP level inside the cells $(p<0.05)$. The decreased mitochondrial membrane potential and ATP level in the cell caused by Res could inhibit the drug efflux mediated by P-gp, resulting in the enhanced intracellular accumulation of Dox. 
A

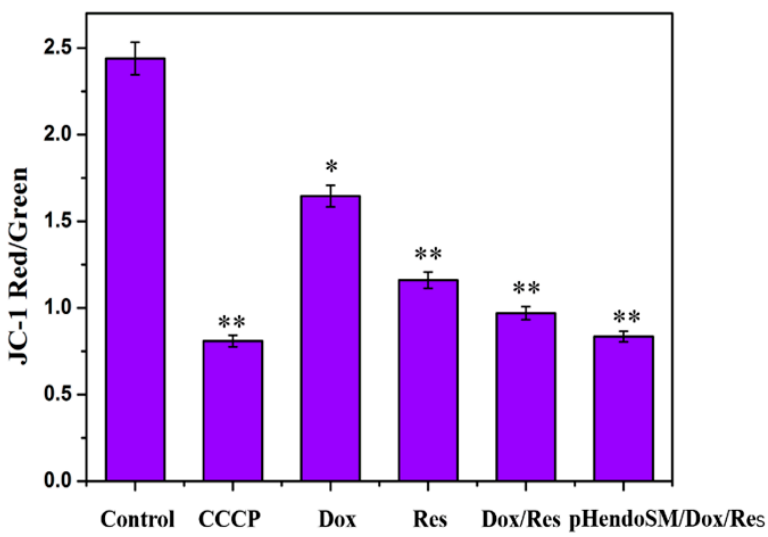

B

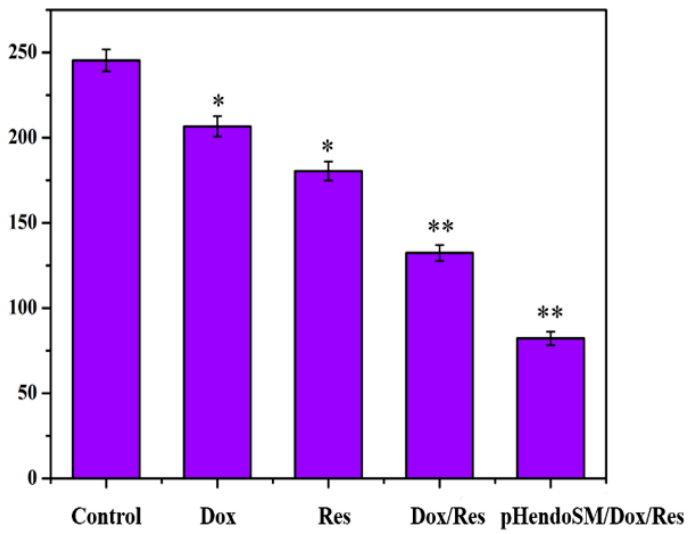

Figure 6. The effect on the mitochondrial membrane potential (A) and intracellular ATP (B) in the MCF-7/ADR cells after $2 \mathrm{~h}$ incubation with different formulations. Data were expressed as mean $\pm \mathrm{SD}$ $(\mathrm{n}=3),{ }^{*} p<0.05,{ }^{* *} p<0.01$ compared with the control group.

\subsubsection{Effect on Cell Apoptosis}

To investigate cell apoptosis initiated by the Dox/Res micelles, the activities of caspase in MCF-7/ADR cells were tested [39]. As illustrated in Figure 7, considerable enhancements of caspase 3 and caspase 9 activities could be found with Res, Dox/Res and pH-endoSM/Dox/Res groups, as compared to those in the free Dox and control groups, while no obvious change of caspase 8 activity was found in all groups. The results suggested that cell apoptosis induced by $\mathrm{pH}$-endoSM/Dox/Res micelles was attributed to the Res-induced mitochondria-dependent signaling pathways. The disruption of mitochondrial membrane potential caused the activation of caspase protein [45]. Caspase 9 could be recruited and activated, resulting in the formation apoptosome complex, which also activated caspase 3 , leading to the following cell death [46].

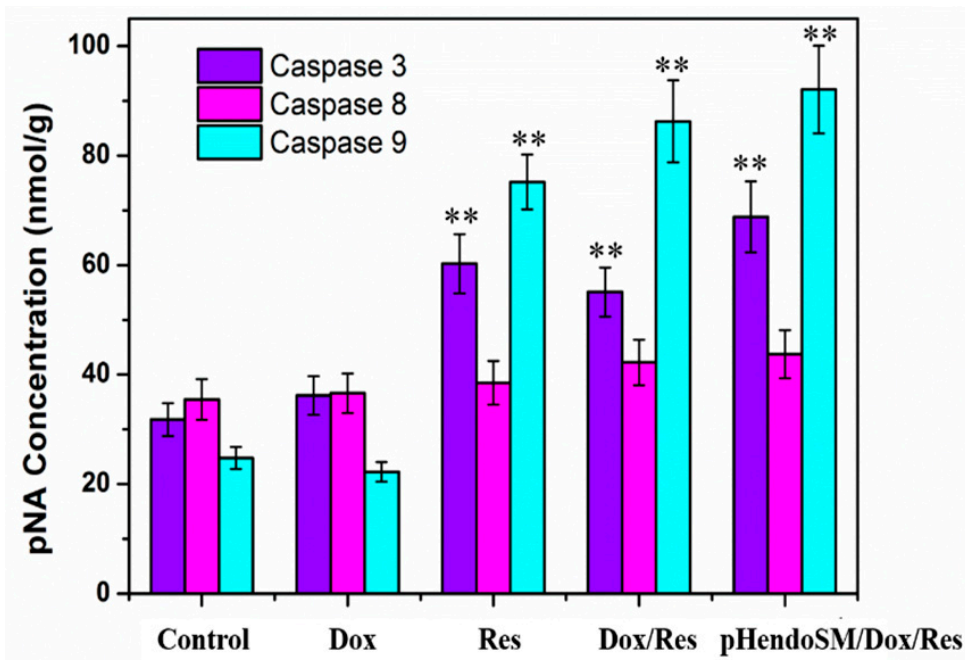

Figure 7. Activity of caspase 3, caspase 8, caspase 9 in MCF-7/ADR cells after treatment with different formulations for $24 \mathrm{~h}$. Data were expressed as mean $\pm \mathrm{SD}(\mathrm{n}=3),{ }^{*} p<0.05,{ }^{* *} p<0.01$ compared with the control group.

All of these results suggest that the micelle reversed the MDR by multiple mechanisms including a co-delivery of Dox and Res, an endo-lysosomal escape mediated by the PHis block, P-gp expression down-regulation and mitochondrial-dependent apoptosis, which produced the synergistic effect for MDR reversal. 


\subsection{In Vivo Biodistribution Studies}

The in vivo biodistribution of $\mathrm{pH}$-endo-sensitive micelles was tested by an optical image system. The micelles loaded at $0.1 \mathrm{wt} \%$ DIR were intravenously injected into tumor-bearing mice. As shown in Figure 8A, the fluorescence intensity of the mPEG-PLA-PHis/DIR micelles was gradually increased in the tumor region after administration. At $0.5 \mathrm{~h}$ post injection, most of DIR/mPEG-PLA-PHis micelles were accumulated in the liver. As time progressed, higher fluorescence could be detected in tumor than other tissues at $12 \mathrm{~h}$ post injection. The strong fluorescence could last for $48 \mathrm{~h}$ in the tumor site. The results indicated that the micelles had a long blood circulation property, facilitating the enhanced permeability and retention (EPR)-mediated tumor targeting. After capturing the last real-time image photo, the tumor tissue and major organs were excised for capturing the ex vivo images (Figure 8B). The strong fluorescence of DIR was observed in the excised tumors, confirming the targeting payload delivery ability of the mPEG-PLA-PHis micelles.

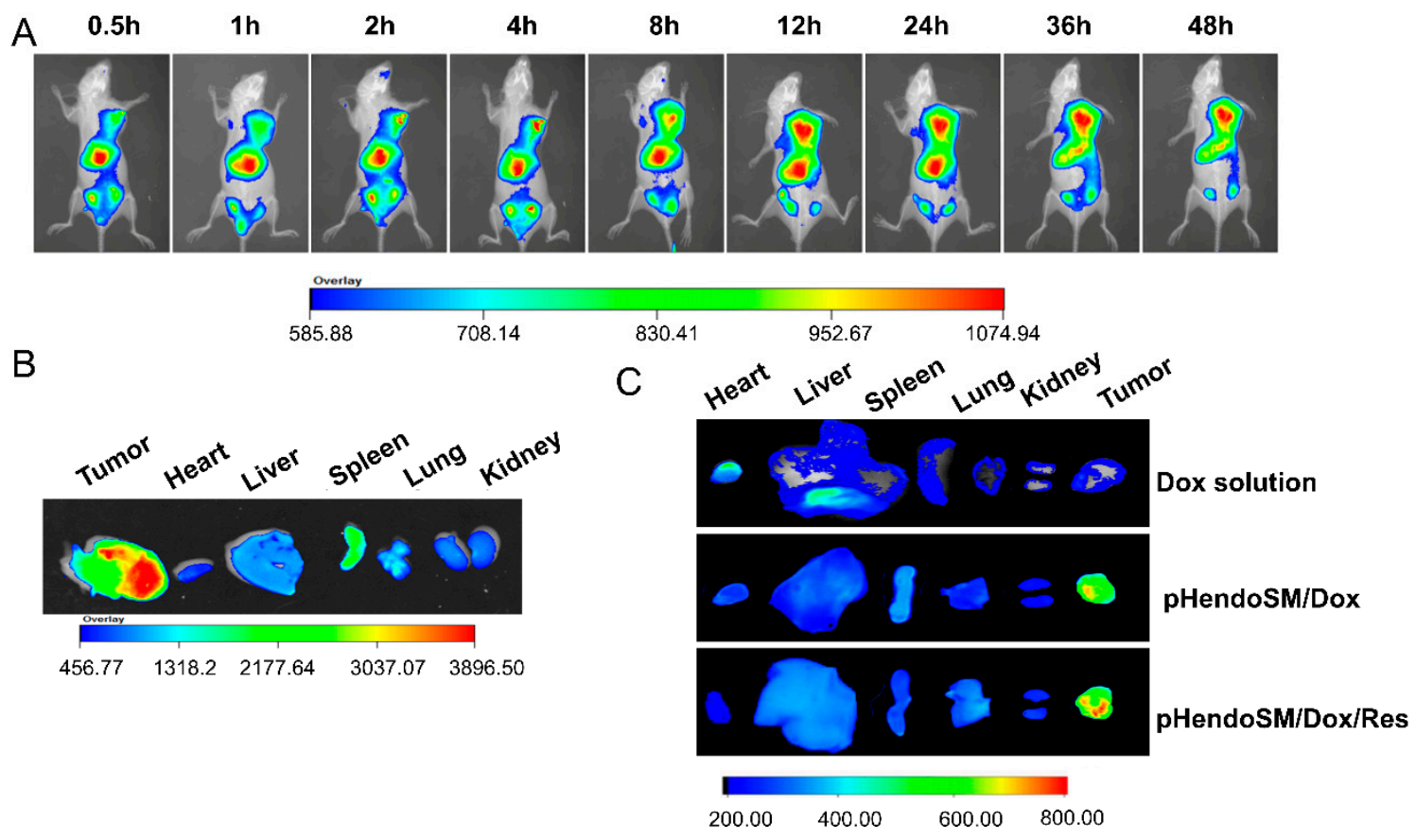

Figure 8. In vivo imaging of MCF-7/ADR tumor-bearing nude mice after intravenous injection with DIR-loaded micelles (A), Ex vivo fluorescence images of tumors and organs collected at $48 \mathrm{~h}$ (B), In vivo distribution of Dox at $48 \mathrm{~h}$ after intravenous injected Dox solution, $\mathrm{pH}$-endoSM/Dox, and $\mathrm{pH}$-endoSM/Dox/Res $(\mathbf{C})(n=3)$.

The biodistribution of Dox delivered by $\mathrm{pH}$-endoSM/Dox/Res was further investigated with Dox solution and $\mathrm{pH}$-endoSM/Dox as control. The Dox fluorescence signals of the main organs and tumor tissues were shown in Figure $8 \mathrm{C}$. After $48 \mathrm{~h}$ administration, The $\mathrm{pH}$-endoSM/Dox/Res exhibited more Dox accumulation in the tumor than the Dox solution and pH-endoSM/Dox. It is consistent with in vitro results that co-delivered Res markedly increased the intracellular accumulation of Dox. It is worth noting that two micelles exhibited lower Dox accumulation in heart than the Dox solution. Dox is known for its serious cardiotoxicity, which limits its clinical application [47].

The copolymer based on micelles were capable of effectively reducing the distribution of DOX in the heart than the DOX solution, offering an alternative to reduce the cardiac toxicity of Dox $[48,49]$.

\subsection{In Vivo Antitumor Efficacy and Safety Evaluation}

In vivo antitumor efficacy was investigated at $48 \mathrm{~h}$ after intravenously administered different formulations. As expected, Dox solution showed little anticancer effect (Figure 9A), which could 
be attributed to the nonspecific distribution of DOX as well as the resistance of the cancer cells to DOX. pH-endoSM/Dox/Res displayed a much stronger tumor inhibition rate than $\mathrm{pH}$-endoSM/Dox, presenting much lower tumor weight (Figure 9A,B). This was in accordance with the in vitro cellular evaluation, which could be attributed to the co-delivery Dox and Res by $\mathrm{pH}$-endoSM for reverting MDR via multiple mechanisms such as the efficient delivery of payloads, down-regulating P-gp expression and inducing cell apoptosis. The images of H\&E staining on tumor tissues (Figure 9C) exhibited that the $\mathrm{pH}$-endoSM/Dox/Res treated group produced much larger areas of necrosed cells than other formulation-treated groups.

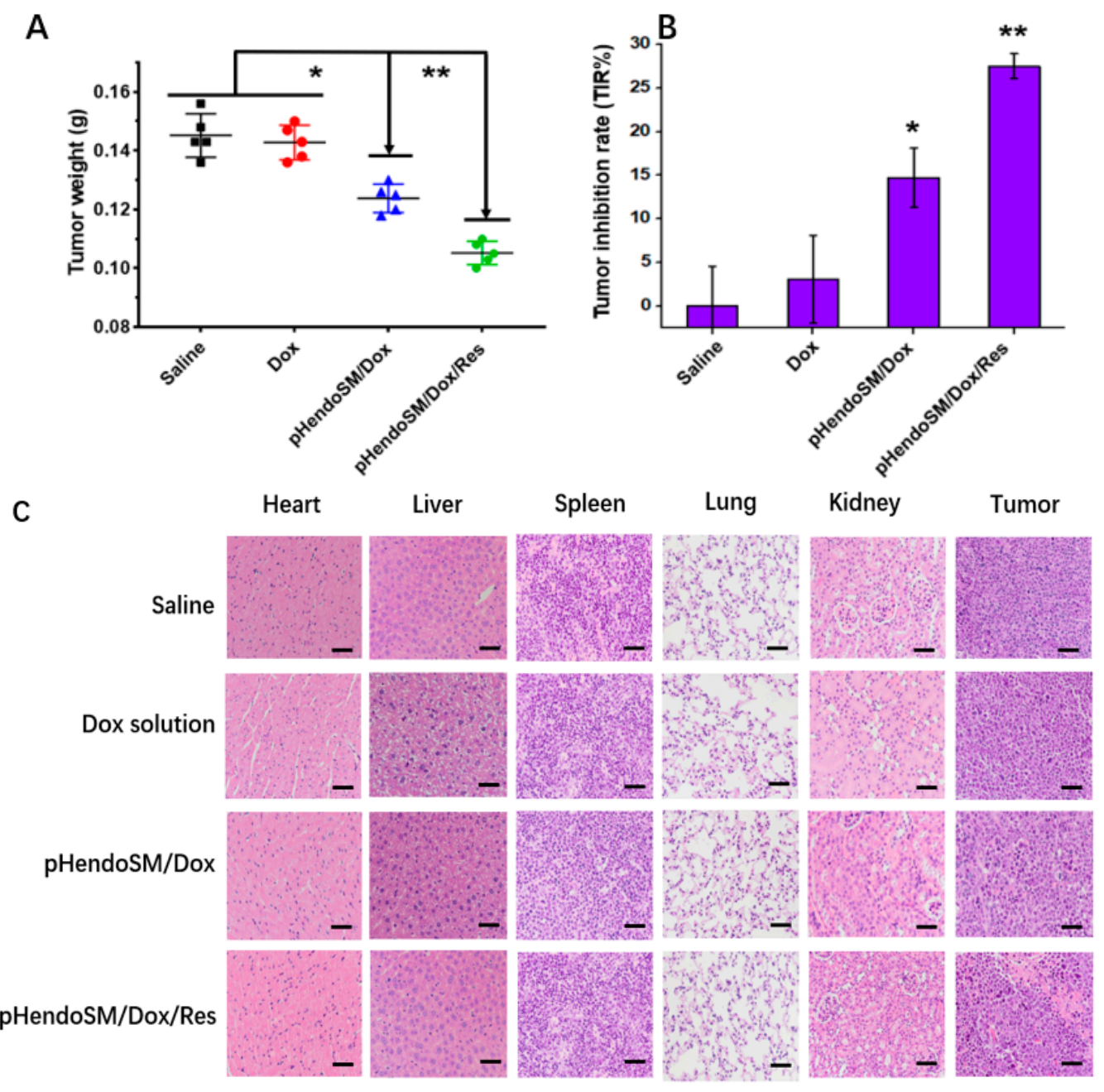

Figure 9. The tumor weight (A) and tumor inhibition rate (TIR\%) (B) of MCF-7/ADR tumor-bearing nude mice at $48 \mathrm{~h}$ after intravenously-injected Saline, Dox solution, $\mathrm{pH}$-endoSM/Dox and $\mathrm{pH}$-endoSM/Dox/Res $(n=5) .{ }^{*} p<0.05,{ }^{* *} p<0.01$ compared with the control group. Morphological evaluation in hematoxylin and eosin (H\&E) sections of the major organs and tumor sites (C). Scale bars $=50 \mu \mathrm{m}$.

In addition, the safety evaluation of different formulations was further investigated by H\&E staining analysis. The Dox solution group exhibited severe cardiotoxicity, hepatotoxicity and nephrotoxicity, as characterized by the significant hydropic degeneration, vacuolar degeneration and spotty necrosis. In contrast, the $\mathrm{pH}$-endoSM/Dox and $\mathrm{pH}$-endoSM/Dox/Res group exhibited much less pathological change in major organs, indicating the excellent safety. 


\section{Conclusions}

In summary, a multifunctional micelle based on the $\mathrm{pH}$ sensitive copolymer of mPEG-PLA-PHis was constructed co-deliver Dox and Res for multi-modulation of doxorubicin resistance tumor cells. The micelles demonstrated excellent encapsulation of Dox and Res as well as the relatively low leakage of payload at the biological condition. The $\mathrm{pH}$-endoSM/Dox/Res micelles that were showed triggered the payloads release because of the protonation of PHis blocks in the micelles under acidic $\mathrm{pH}$. The co-delivery of Res and Dox with the micelles exhibited the significant synergistic effect and enhanced cytotoxicity against MCF-7/ADR cells. The cellular distribution of Dox indicated that the Phis-based copolymer facilitated the effective endo-lysosomal escape of Dox and the translocation to the nucleus. The $\mathrm{pH}$-endoSM/Dox/Res micelles were found to reverse MDR in a multiple way, including enhancing the intracellular accumulation of Dox by copolymer-facilitated endosomal escape, and down-regulating the expression of P-gp, reducing the membrane potential of the mitochondrial and declining ATP level inside cells, and triggering mitochondria-dependent cell apoptosis. The $\mathrm{pH}$-endo-sensitive micelles exhibited more Dox accumulation in the tumor and less Dox distribution in the major organ, helping to enhance anti-tumor efficacy and reduce the Dox-related toxicity. The $\mathrm{pH}$-endoSM/Dox/Res micelles have been demonstrated as a potential delivery system to reverse the MDR.

Author Contributions: L.J. and M.Q. conceived the idea and edited the manuscript. L.J., N.J. and Y.G. designed and carried out the experiments. D.C., H.H., X.Z. contributed for the providing technical support. M.Q. revised the manuscript, financed the project and supervised the whole research work.

Funding: This project was supported by the National Natural Science Foundation of China (No. 81573372) and Career Development Support Plan for Young and Middle-aged Teachers in Shenyang Pharmaceutical University (ZQN2014A03).

Conflicts of Interest: The authors declare that they have no competing interests.

\section{References}

1. Yuan, Y.; Cai, T.; Xia, X.; Zhang, R.; Chiba, P.; Cai, Y. Nanoparticle delivery of anticancer drugs overcomes multidrug resistance in breast cancer. Drug Deliv. 2016, 23, 3350-3357. [CrossRef] [PubMed]

2. Kayani, Z.; Firuzi, O.; Bordbar, A.K. Doughnut-shaped bovine serum albumin nanoparticles loaded with doxorubicin for overcoming multidrug-resistant in cancer cells. Int. J. Biol. Macromol. 2018, 107, 1835-1843. [CrossRef] [PubMed]

3. Vijayaraghavalu, S.; Dermawan, J.K.; Cheriyath, V.; Labhasetwar, V. Highly synergistic effect of sequential treatment with epigenetic and anticancer drugs to overcome drug resistance in breast cancer cells is mediated via activation of p21 gene expression leading to G2/M cycle arrest. Mol. Pharm. 2013, 10, 337-352. [CrossRef] [PubMed]

4. Chun, S.Y.; Kwon, Y.S.; Nam, K.S.; Kim, S. Lapatinib enhances the cytotoxic effects of doxorubicin in MCF-7 tumorspheres by inhibiting the drug efflux function of ABC transporters. Biomed. Pharm. 2015, 72, 37-43. [CrossRef] [PubMed]

5. Szakacs, G.; Paterson, J.K.; Ludwig, J.A.; Genthe, C.B.; Gottesman, M.M. Targeting multidrug resistance in cancer. Nat. Rev. Drug Discov. 2006, 5, 219-234. [CrossRef] [PubMed]

6. Zhang, Y.; Zhou, T.; Duan, J.; Xiao, Z.; Li, G.; Xu, F. Inhibition of P-glycoprotein and Glutathione S-transferase-pi mediated resistance by fluoxetine in MCF-7/ADM cells. Biomed. Pharmacother. 2013, 67, 757-762. [CrossRef]

7. Yu, P.; Cheng, X.; Du, Y.; Yang, L.; Huang, L. Significance of MDR-related proteins in the postoperative individualized chemotherapy of gastric cancer. J. Cancer Res. Ther. 2015, 11, 46.

8. Bal, C.; Baldeyrou, B.; Moz, F.; Lansiaux, A.; Colson, P.; Kraus-Berthier, K.; Léonce, S.; Pierré, A.; Boussard, M.F.; Rousseau, A.; et al. Novel antitumor indenoindole derivatives targeting DNA and topoisomerase II. Biochem. Pharmacol. 2004, 68, 1911-1922.

9. Kartal-Yandim, M.; Adan-Gokbulut, A.; Baran, Y. Molecular mechanisms of drug resistance and its reversal in cancer. Crit. Rev. Biotechnol. 2016, 36, 716-726. [CrossRef] 
10. Sjostedt, N.; Sjöstedt, N.; Holvikari, K.; Tammela, P.; Kidron, H. Inhibition of Breast Cancer Resistance Protein and Multidrug Resistance Associated Protein 2 by Natural Compounds and Their Derivatives. Mol. Pharm. 2017, 14, 135-146. [CrossRef]

11. Yu, J.; Zhu, L.; Zheng, H.; Gong, X.; Jiang, H.; Chen, J.; Li, Y.; Zheng, H.; Qi, X.; Wang, Y.; et al. Sulfotransferases and Breast Cancer Resistance Protein Determine the Disposition of Calycosin in Vitro and in Vivo. Mol. Pharm. 2017, 14, 2917-2929. [CrossRef]

12. Zhang, Y.X.; Zhao, Y.Y.; Shen, J.; Sun, X.; Liu, Y.; Liu, H.; Wang, Y.; Wang, J. Nanoenabled Modulation of Acidic Tumor Microenvironment Reverses Anergy of Infiltrating T Cells and Potentiates Anti-PD-1 Therapy. Nano Lett. 2019, 19, 2774-2783. [CrossRef]

13. Wang, F.; Zhang, D.; Zhang, Q.; Chen, Y.; Zheng, D.; Hao, L.; Duan, C.; Jia, L.; Liu, G.; Liu, Y. Synergistic effect of folate-mediated targeting and verapamil-mediated P-gp inhibition with paclitaxel -polymer micelles to overcome multi-drug resistance. Biomaterials 2011, 32, 9444-9456. [CrossRef]

14. Hong, W.; Chen, D.; Zhang, X.; Zeng, J.; Hu, H.; Zhao, X.; Qiao, M. Reversing multidrug resistance by intracellular delivery of Pluronic ${ }^{\circledR}$ P85 unimers. Biomaterials 2013, 34, 9602-9614. [CrossRef]

15. Engblom, P.; Pulkkinen, J.O.; Rantanen, V.; Hirvonen, H.; Kulmala, J.; Grènman, R.; Grènman, S. Effects of Paclitaxel With or Without Cremophor EL on Cellular Clonogenic Survival and Apoptosis. Eur. J. Cancer 1999, 35, 5. [CrossRef]

16. Werle, M. Natural and synthetic polymers as inhibitors of drug efflux pumps. Pharm. Res. 2008, 25, 500-511. [CrossRef]

17. Guo, Y.; Chu, M.; Tan, S.; Zhao, S.; Liu, H.; Otieno, B.O.; Yang, X.; Xu, C.; Zhang, Z. Chitosan-g-TPGS nanoparticles for anticancer drug delivery and overcoming multidrug resistance. Mol. Pharm. 2014, 11, 59-70. [CrossRef]

18. Zhang, W.; Shi, Y.; Chen, Y.; Ye, J.; Sha, X.; Fang, X. Multifunctional Pluronic P123/F127 mixed polymeric micelles loaded with paclitaxel for the treatment of multidrug resistant tumors. Biomaterials 2011, 32, 2894-2906. [CrossRef]

19. Krishna, R.; Mayer, L.D. Multidrug resistance (MDR) in cancer: Mechanisms, reversal using modulators of MDR and the role of MDR modulators in influencing the pharmacokinetics of anticancer drugs. Eur. J. Pharm. Sci. 2000, 11, 265-283. [CrossRef]

20. Ford, J.M. Modulators of multidrug resistance: Preclinical studies. Hematol. Oncol. Clin. N. Am. 1995, 9, 337-362. [CrossRef]

21. Qiu, L.; Qiao, M.; Chen, Q.; Tian, C.; Long, M.; Wang, M.; Li, Z.; Hu, W.; Li, G.; Cheng, L.; et al. Enhanced effect of $\mathrm{pH}$-sensitive mixed copolymer micelles for overcoming multidrug resistance of doxorubicin. Biomaterials 2014, 35, 9877-9887. [CrossRef]

22. Fan, L.; Li, F.; Zhang, H.; Wang, Y.; Cheng, C.; Li, X.; Gu, C.; Yang, Q.; Wu, H.; Zhang, S. Co-delivery of PDTC and doxorubicin by multifunctional micellar nanoparticles to achieve active targeted drug delivery and overcome multidrug resistance. Biomaterials 2010, 31, 5634-5642. [CrossRef]

23. Duan, X.; Xiao, J.; Yin, Q.; Zhang, Z.; Yu, H.; Mao, S.; Li, Y. Smart pH-Sensitive and TemporalControlled Polymeric Micelles for Effective Combination Therapy of Doxorubicin and Disulfiram. ACS Nano 2013, 7, 12. [CrossRef]

24. Guo, X.; Wei, X.; Jing, Y.; Zhou, S. Size changeable nanocarriers with nuclear targeting for effectively overcoming multidrug resistance in cancer therapy. Adv. Mater. 2015, 27, 6450-6456. [CrossRef]

25. Yu, H.; Cui, Z.; Yu, P.; Guo, C.; Feng, B.; Jiang, T.; Wang, S.; Yin, Q.; Zhong, D.; Yang, X.; et al. pH-and NIR light-responsive micelles with hyperthermia-triggered tumor penetration and cytoplasm drug release to reverse doxorubicin resistance in breast cancer. Adv. Funct. Mater. 2015, 25, 2489-2500. [CrossRef]

26. Zhang, Y.K.; Wang, Y.J.; Gupta, P.; Chen, Z.S. Multidrug resistance proteins (MRPs) and cancer therapy. AAPS J. 2015, 17, 802-812. [CrossRef]

27. Jia, N.; Ye, Y.; Wang, Q.; Zhao, X.; Hu, H.; Chen, D.; Qiao, M. Preparation and evaluation of poly( 1 -histidine) based $\mathrm{pH}$-sensitive micelles for intracellular delivery of doxorubicin against MCF-7/ADR cells. Asian J. Pharm. Sci. 2017, 12, 433-441. [CrossRef]

28. Tang, B.; Fang, G.; Gao, Y.; Liu, Y.; Liu, J.; Zou, M.; Wang, L.; Cheng, G. Lipid-albumin nanoassemblies co-loaded with borneol and paclitaxel for intracellular drug delivery to C6 glioma cells with P-gp inhibition and its tumor targeting. Asian J. Pharm. Sci. 2015, 10, 363-371. [CrossRef] 
29. Jang, M.; Cai, L.; Udeani, G.O.; Slowing, K.V.; Thomas, C.F.; Beecher, C.W.; Fong, H.H.; Farnsworth, N.R.; Kinghorn, A.D.; Mehta, R.G.; et al. Cancer Chemopreventive Activity of Resveratrol, a Natural Product Derived from Grapes. Science 1997, 275, 23. [CrossRef]

30. Schneidera, Y.; Vincent, F.; Duranton, B.; Badolo, L.; Gossé, F.; Bergmann, C.; Seiler, N.; Raul, F. Anti-proliferative effect of resveratrol, a natural component of grapes and wine, on human colonic cancer cells. Cancer Lett. 2000, 158, 7. [CrossRef]

31. Rai, G.; Mishra, S.; Suman, S.; Shukla, Y. Resveratrol improves the anticancer effects of doxorubicin in vitro and in vivo models: A mechanistic insight. Phytomedicine 2016, 23, 233-242. [CrossRef]

32. Zhang, X.; Chen, D.; Ba, S.; Zhu, J.; Zhang, J.; Hong, W.; Zhao, X.; Hu, H.; Qiao, M. Poly(l-histidine) based triblock copolymers: $\mathrm{pH}$ induced reassembly of copolymer micelles and mechanism underlying endolysosomal escape for intracellular delivery. Biomacromolecules 2014, 15, 4032-4045. [CrossRef]

33. Altreuter, D.H.; Dordick, J.S.; Clark, D.S. Nonaqueous Biocatalytic Synthesis of New Cytotoxic Doxorubicin Derivatives: Exploiting Unexpected Differences in the Regioselectivity of Salt Activated and Solubilized Subtilisin. J. Am. Chem. Soc. 2002, 124, 6. [CrossRef]

34. Hao, T.; Chen, D.; Liu, K.; Qi, Y.; Tian, Y.; Sun, P.; Li, Y.; Li, Z. Micelles of d-alpha-Tocopheryl Polyethylene Glycol 2000 Succinate (TPGS 2K) for Doxorubicin Delivery with Reversal of Multidrug Resistance. ACS Appl. Mater. Interfaces 2015, 7, 18064-18075. [CrossRef]

35. Hong, W.; Chen, D.; Jia, L.; Gu, J.; Hu, H.; Zhao, X.; Qiao, M. Thermo- and pH-responsive copolymers based on PLGA-PEG-PLGA and poly(L-histidine): Synthesis and in vitro characterization of copolymer micelles. Acta Biomater. 2014, 10, 1259-1271. [CrossRef]

36. Assanhou, A.G.; Li, W.; Zhang, L.; Xue, L.; Kong, L.; Sun, H.; Mo, R.; Zhang, C. Reversal of multidrug resistance by co-delivery of paclitaxel and lonidamine using a TPGS and hyaluronic acid dual-functionalized liposome for cancer treatment. Biomaterials 2015, 73, 284-295. [CrossRef]

37. Zhang, J.; Du, Z.; Pan, S.; Shi, M.; Li, J.; Yang, C.; Hu, H.; Qiao, M.; Chen, D. Overcoming Multidrug Resistance by Codelivery of MDR1-Targeting siRNA and Doxorubicin Using EphA10-Mediated pH-Sensitive Lipoplexes: In Vitro and In Vivo Evaluation. ACS Appl. Mater. Interfaces 2018, 10, 21590-21600. [CrossRef]

38. Gao, Y.; Jia, L.; Wang, Q.; Hu, H.; Zhao, X.; Chen, D.; Qiao, M. pH/Redox Dual-Responsive Polyplex with Effective Endosomal Escape for Codelivery of siRNA and Doxorubicin against Drug-Resistant Cancer Cells. ACS Appl. Mater. Interfaces 2019, 11, 16296-16310. [CrossRef]

39. Liang, D.; Wang, A.; Yang, Z.; Liu, Y.; Qi, X. Enhance Cancer Cell Recognition and Overcome Drug Resistance Using Hyaluronic Acid and alpha-Tocopheryl Succinate Based Multifunctional Nanoparticles. Mol. Pharm 2015, 12, 2189-2202. [CrossRef]

40. Zhou, M.; Zhang, X.; Xie, J.; Qi, R.; Lu, H.; Leporatti, S.; Chen, J.; Hu, Y. pH-Sensitive Poly(beta-amino ester)s Nanocarriers Facilitate the Inhibition of Drug Resistance in Breast Cancer Cells. Nanomaterials 2018, 8, 952. [CrossRef]

41. Zhu, J.; Qiao, M.; Wang, Q.; Ye, Y.; Ba, S.; Ma, J.; Hu, H.; Zhao, X.; Chen, D. Dual-responsive polyplexes with enhanced disassembly and endosomal escape for efficient delivery of siRNA. Biomaterials 2018, 162, 47-59. [CrossRef]

42. Nicklisch, S.C.; Rees, S.D.; McGrath, A.P.; Gökirmak, T.; Bonito, L.T.; Vermeer, L.M.; Cregger, C.; Loewen, G.; Sandin, S.; Chang, G.; et al. Global marine pollutants inhibit P-glycoprotein: Environmental levels, inhibitory effects, and cocrystal structure. Sci. Adv. 2016, 2, e1600001. [CrossRef]

43. McCormick, J.W.; Vogel, P.D.; Wise, J.G. Multiple drug transport pathways through human P-glycoprotein. Biochemistry 2015, 54, 4374-4390. [CrossRef]

44. Dartier, J.; Lemaitre, E.; Chourpa, I.; Goupille, C.; Servais, S.; Chevalier, S.; Mahéo, K.; Dumas, J.K. ATP-dependent activity and mitochondrial localization of drug efflux pumps in doxorubicin-resistant breast cancer cells. Biochim. Et Biophys. Acta Gen. Subj. 2017, 1861, 1075-1084. [CrossRef]

45. Lee, H.J.; Lee, E.O.; Ko, S.G.; Bae, H.S.; Kim, C.H.; Ahn, S.K.; Lu, J.; Kim, S.H. Mitochondria-cytochrome C-caspase-9 cascade mediates isorhamnetin-induced apoptosis. Cancer Lett. 2008, 270, 342-353. [CrossRef]

46. St-Louis, M.C.; Archambault, D. The equine arteritis virus induces apoptosis via caspase- 8 and mitochondria-dependent caspase-9 activation. Virology 2007, 367, 147-155. [CrossRef]

47. Pugazhendhi, A.; Edison, T.N.J.I.; Velmurugan, B.K.; Jacob, J.A.; Karuppusamye, I. Toxicity of Doxorubicin (Dox) to different experimental organ systems. Life Sci. 2018, 200, 26-30. [CrossRef] 
48. Fang, Y.; Wang, H.; Dou, H.J.; Fan, X.; Fei, X.C.; Wang, L.; Cheng, S.; Janin, A.; Wang, L.; Zhao, W.L. Doxorubicin-loaded dextran-based nano-carriers for highly efficient inhibition of lymphoma cell growth and synchronous reduction of cardiac toxicity. Int. J. Nanomed. 2018, 13, 5673. [CrossRef]

49. Pawar, S.; Shevalkar, G.; Vavia, P. Glucosamine-anchored doxorubicin-loaded targeted nano-niosomes: Pharmacokinetic, toxicity and pharmacodynamic evaluation. J. Drug Target. 2016, 24, 730-743. [CrossRef]

(C) 2019 by the authors. Licensee MDPI, Basel, Switzerland. This article is an open access article distributed under the terms and conditions of the Creative Commons Attribution (CC BY) license (http://creativecommons.org/licenses/by/4.0/). 